\title{
COVID-19 Laboratory Testing Capacity in 13 African Countries
}

\section{Adebisi $\mathrm{YA}^{1,2,3 *}$, Rabe $\mathrm{A}^{4}$, Alaran $\mathrm{AJ}^{5}$, Babatunde $\mathrm{AO}^{6}$, Uzairue $\mathrm{LI}^{7,8}$ and Lucero Prisno $\mathrm{DE}^{9}$}

${ }^{1}$ Global Health Focus, Nigeria

${ }^{2}$ National Agency for Food and Drug Administration and Control, Nigeria

${ }^{3}$ Faculty of Pharmacy, University of Ibadan, Nigeria

${ }^{4}$ School of Public Health, Faculty of Medicine, UK

${ }^{5}$ Faculty of Pharmaceutical Sciences, University of Ilorin, Nigeria

${ }^{6}$ Faculty of Clinical Sciences, University of Ibadan, Nigeria

${ }^{7}$ Department of Medical Laboratory Science, Federal University Oye Ekiti, Nigeria

${ }^{8}$ Department of Microbiology, Federal University of Agriculture, Nigeria

${ }^{9}$ Department of Global Health and Development, London School of Hygiene and Tropical Medicine, UK

*Corresponding author: Yusuff Adebayo Adebisi, Global Health Focus, Ibadan, Nigeria, Email: adebisiyusuff23@gmail.com

\section{Review Article \\ Volume 5 Issue 4}

Received Date: November 29, 2021

Published Date: December 28, 2021

DOI: $10.23880 /$ eij-16000214

\section{Abstract}

Introduction: Laboratory testing plays a crucial role in response to infectious diseases outbreaks, including the on-going global COVID-19 pandemic. Herein, we assessed the laboratory testing capacity of 13 African countries and identify the challenges they face surrounding COVID-19 testing.

Method: We conducted a comprehensive narrative review of scholarly literature published between January 2020 and August 2021 in PubMed, Medline, ScienceDirect, PubMed Central, and Google Scholar to assess laboratory testing capacity and associated challenges in 13 African countries prioritized by the World Health Organization i.e., Mauritius, Algeria, Nigeria, Angola, Cote d'Ivoire, the Democratic Republic of the Congo, Ghana, Ethiopia, South Africa, Kenya, Zambia, Tanzania, and Uganda. Supplementary data were also gathered from country reports, WHO reports, websites of key organizations, policy brief, newsletter, and other reports as well as through systematic google search. We also reviewed reference lists of relevant sources to gather data for the study.

Result: The 13 African countries have ramped up COVID-19 testing using Reverse Transcription Polymerase Chain Reaction, the gold standard for COVID-19 diagnosis, and other laboratory testing methods. With respect to the population size, Mauritius had conducted the highest number of COVID-19 tests while, South Africa conducted the highest number of tests among the countries. However, most African countries included had low testing capacity relative to their population size. Some of the challenges identified included inadequate test kits and other logistical constraints, weak surveillance systems, difficulty in transporting test samples, a dearth of human resources, and poor management of laboratory data.

Conclusion: This study revealed that there is low laboratory testing capacity in the selected African countries. Laboratory response to COVID-19 has multiple challenges. There is a need to invest in strengthening infectious diseases laboratory systems in Africa.

Keywords: COVID-19; Laboratory Testing Capacity; Public Health; Global Health, Africa 


\section{Epidemiology International Journal}

Abbreviations: WHO: World Health Organization; IPA: Institute Pasteur Algeria; NIBR: National Institute of Biomedical Research; NMIMR: Noguchi Memorial Institute for Medical Research; NCDC: Nigeria Centre for Disease Control; NHLS: National Health Laboratory Service; UTH: University Teaching Hospital; BSL-2: Biosafety Level-2.

\section{Introduction}

COVID-19 is a threat to health systems globally $[1,2]$. Since its emergence in Wuhan, China in 2019, the global outbreak has continued to demonstrate itself as an unprecedented public health emergency in all parts of the world, including Africa [3]. It was declared a pandemic by the World Health Organization (WHO) in March 2020 [4]. As of 1 September 2021, there have been 217,558,771 confirmed COVID-19 cases globally with more than 4.5 million deaths [5]. The first index case in Africa was reported in Egypt on 14 February 2020 [3]. To date, over 5 million cases and more than 170,000 deaths have been reported on the continent [5].

At the beginning of the outbreak, only a paltry amount of information about the nature of the novel disease was obtainable. By 4 January 2020, the WHO reported a cluster of pneumonia cases in the Hubei province; a flagship technical publication that contained risk assessment and advice was immediately made available to the scientific communities and public media [6]. In the following week, China shared the genetic sequence of COVID-19. This accounted for the first laboratory diagnosis of the disease [7]. Deeply concerned both by the alarming rate of spread and the severity of the disease and having established evidence of human-to-human (community) transmission, the WHO issued the international community its Strategic Preparedness and Response Plans. In this document, the WHO emphasized that containment is of enormous importance and can only be achieved through case finding, contact tracing, and quarantine during the incubation period [8]. Thus, a huge emphasis was placed on laboratory testing because of undifferentiated clinical symptoms that could be attributed to various aetiologies apart from COVID-19.

As part of scaling up preparedness efforts and response to the disease, the WHO had identified 13 priority African countries (Algeria, Angola, Cote d'Ivoire, Democratic Republic of Congo, Ethiopia, Ghana, Kenya, Mauritius, Nigeria, South Africa, Tanzania, Uganda, Zambia) which either have direct links or a high volume of travel to China [9] However, the first documented case was imported to the continent through Egypt. This case was identified to have arrived from Europe rather than China where the virus originated [2]. Within three months, the cases had spread throughout the continent, with Lesotho, the last sovereign state to have contracted COVID-19, reporting a case on May 13,2020 [10]. Because the testing capacity for the disease in Africa was very limited- only two countries (South Africa and Senegal) in Africa could test for COVID-19 at the beginning of the outbreak in January 2020- and because Africa have always had weaker health systems, it was predicted that the bludgeoning effect of the virus would be most devastating in the continent [1].

However, as the pandemic unfolded, Africa appears to be the least impacted continent by this deadly pandemic. It must be emphasised, however, that one possible reason for the low number of cases in Africa compared to other continents is under-diagnosis of cases due to insufficient laboratory capacity in many countries in the region; and experts have suggested that there could be a significant mismatch between number of cases reported and actual number of cases, thereby undermining the appreciation of full impact of the disease $[1,2,11]$. Laboratory testing plays a crucial role in the prevention and management of infectious disease outbreaks [12]. In order to develop the most strategic approaches to curtail the burden of COVID-19 in Africa, laboratory testing capacity in the region must be effectively strengthened. The priority African countries identified by WHO largely overlap with countries with highly dense populations and high incidence of COVID-19 cases. Currently, these regions are in different stages of national and subnational laboratory capacity in terms of equipment, human resources, and stockpiles of required reagents and supplies. In this paper, we assessed the laboratory testing capacity of the 13 WHOPrioritized African countries (Algeria, Angola, Cote d'Ivoire, Democratic Republic of Congo, Ethiopia, Ghana, Kenya, Mauritius, Nigeria, South Africa, Tanzania, Uganda, and Zambia), and identified the challenges facing COVID-19 testing in the countries.

\section{Materials and Methods}

We conducted a comprehensive narrative review to assess the laboratory testing capacity of the 13 WHOPrioritized African countries (Algeria, Angola, Cote d'Ivoire, Democratic Republic of Congo, Ethiopia, Ghana, Kenya, Mauritius, Nigeria, South Africa, Tanzania, Uganda, and Zambia) and identify the challenges facing COVID-19 laboratory testing. Searches were conducted in PubMed, Google Scholar, Medline, ScienceDirect, and PubMed Central using the following search terms: "COVID-19", "SARS-CoV-2", "2019-nCoV", + "Diagnostic Testing", 'Laboratory Testing", "Molecular Testing", "Serological testing" "Antigen Testing" "Mass Testing" "PCR Testing", "RT-PCR Testing" " $\{+$ Each African Countries - Algeria, Angola, Côte d'Ivoire, the Democratic Republic of the Congo, Ethiopia, Ghana, Kenya, Mauritius, Nigeria, South Africa, Tanzania, Uganda, and Zambia\}. 


\section{Epidemiology International Journal}

Only studies published in English Language from January 2020 to August 2021 on the topic were included while the exclusion criterion was any other data sources that do not provide information regarding COVID-19 laboratory testing in the 13 African countries. Three members of the research team (YAA, AJA, and AOB) were involved in the literature review to gather data for this study independently. The collected articles were managed using Endnote Reference Manager Software version X8 with a prior review of the title and abstract of the included papers. In case of any duplication of references or disagreement, a consensus was reached through discussion. Secondary verification of the data and review for appropriateness of inclusion were conducted by four researchers (YAA, AR, DELP, and LI). The investigators also reviewed relevant articles that were taken from reference lists of the articles identified in our systematic search. Supplementary data were also gathered from country reports, newsletters, commentaries, policy briefs, and other reports as well as direct Google search as it was inferred that some of the relevant sources are not published in peer- reviewed academic journals because they are not empirical studies but policy papers. The extracted data were discussed in a narrative to answer the aim of the study.

\section{Results and Discussion}

\section{COVID-19 Testing Capacity in Africa}

Generally, COVID-19 can be diagnosed using the following laboratory techniques: molecular methods (nucleic acid testing), serology (protein testing), rapid antigen test (point of care testing), cell culture, and computed tomography. As at the time of writing this paper, 47 countries in Africa can test for COVID-19 using PCR, which is the gold standard for diagnosis [13]. In Table 1, we revealed the number of COVID-19 tests conducted, gold standard laboratory testing methods and centers in the 13 African countries with a remark. We also reported the number of laboratory test conducted per 1 million of the African population [14], See Figure 1.

\begin{tabular}{|c|c|c|c|c|c|c|c|}
\hline 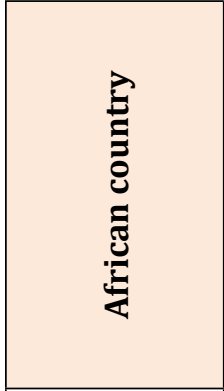 & 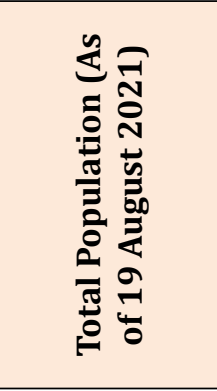 & 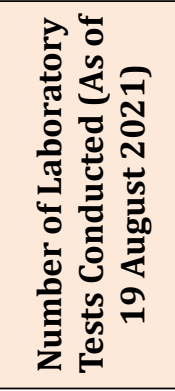 & 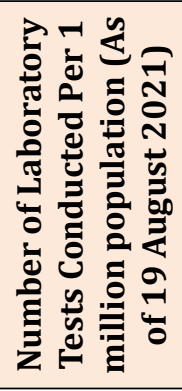 & 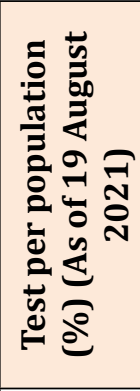 & 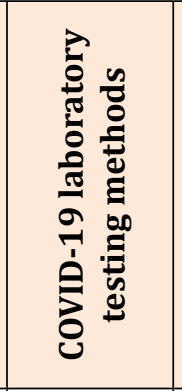 & 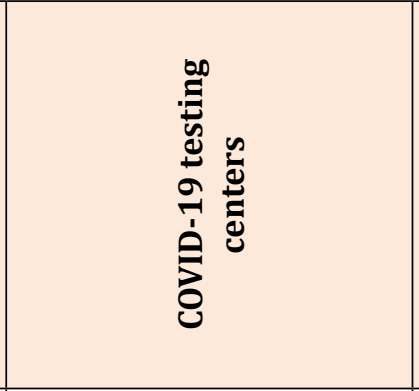 & $\frac{\mathscr{y}}{\underline{Z}}$ \\
\hline Algeria & $4,47,42,779$ & $2,30,861$ & 5,160 & 0.5 & $\begin{array}{c}\text { The gold } \\
\text { standard is } \\
\text { RT-PCR. }\end{array}$ & $\begin{array}{c}\text { More than 29 IPA } \\
\text { laboratories and other } \\
\text { private laboratories, } \\
\text { university COVID-19 } \\
\text { testing centers and } \\
\text { hospital laboratories. }\end{array}$ & $\begin{array}{l}\text { Low testing rates } \\
\text { relative to the } \\
\text { country's population }\end{array}$ \\
\hline Angola & $3,40,14,338$ & $8,26,140$ & 24,288 & 2.4 & $\begin{array}{c}\text { The gold } \\
\text { standard is } \\
\text { RT-PCR. }\end{array}$ & $\begin{array}{c}\text { More than } 5 \text { COVID-19 } \\
\text { laboratories. }\end{array}$ & $\begin{array}{c}\text { Low testing rates } \\
\text { relative to the } \\
\text { country's population }\end{array}$ \\
\hline Cote d'Ivoire & $2,71,12,813$ & $8,45,410$ & 31,181 & 3.1 & $\begin{array}{c}\text { The gold } \\
\text { standard is } \\
\text { RT-PCR. }\end{array}$ & $\begin{array}{c}45 \text { testing centers was } \\
\text { proposed; } 9 \text { centers } \\
\text { has been dedicated for } \\
\text { international travel testing. }\end{array}$ & $\begin{array}{c}\text { Low testing rates } \\
\text { relative to the } \\
\text { country's population }\end{array}$ \\
\hline $\begin{array}{l}\text { Democratic } \\
\text { Republic of } \\
\text { Congo } \\
\end{array}$ & $9,26,19,502$ & $3,02,022$ & 3,261 & 0.3 & \begin{tabular}{|c|} 
The gold \\
standard is \\
RT-PCR.
\end{tabular} & $\begin{array}{c}\text { Various laboratories across } \\
\text { different provinces, and } \\
\text { other private centers. }\end{array}$ & $\begin{array}{c}\text { Low testing rates } \\
\text { relative to the } \\
\text { country's population }\end{array}$ \\
\hline Ethiopia & $11,81,65,839$ & $31,42,116$ & 26,591 & 2.7 & $\begin{array}{c}\text { The gold } \\
\text { standard is } \\
\text { RT-PCR. }\end{array}$ & $\begin{array}{c}\text { More than } 70 \text { COVID-19 } \\
\text { laboratories, university } \\
\text { laboratories, research } \\
\text { institutes, hospital } \\
\text { laboratories, and private } \\
\text { centers }\end{array}$ & $\begin{array}{l}\text { Low testing rates } \\
\text { relative to the } \\
\text { country's population }\end{array}$ \\
\hline
\end{tabular}




\section{Epidemiology International Journal}

\begin{tabular}{|c|c|c|c|c|c|c|c|}
\hline Ghana & $3,18,02,941$ & $15,44,519$ & 48,565 & 4.9 & $\begin{array}{c}\text { The gold } \\
\text { standard is } \\
\text { RT-PCR. }\end{array}$ & $\begin{array}{l}\text { COVID-19 testing centers } \\
\text { across private laboratories, } \\
\text { research institution, } \\
\text { universities and hospitals. }\end{array}$ & $\begin{array}{c}\text { Low testing rates } \\
\text { relative to the } \\
\text { country's population }\end{array}$ \\
\hline Kenya & $5,51,04,013$ & $22,87,443$ & 41,511 & 4.2 & $\begin{array}{c}\text { The gold } \\
\text { standard is } \\
\text { RT-PCR. }\end{array}$ & $\begin{array}{l}\text { More than } 45 \text { COVID-19 } \\
\text { testing laboratories across } \\
\text { government hospitals and } \\
\text { private laboratories among } \\
\text { others. }\end{array}$ & $\begin{array}{l}\text { Low testing rates } \\
\text { relative to the } \\
\text { country's population }\end{array}$ \\
\hline Mauritius & $12,74,152$ & $3,58,675$ & $2,81,501$ & 28 & $\begin{array}{c}\text { The gold } \\
\text { standard is } \\
\text { RT-PCR. }\end{array}$ & $\begin{array}{l}\text { More than four COVID-19 } \\
\text { testing PCR laboratories } \\
\text { which is found across } \\
\text { private laboratories, and } \\
\text { hospitals. }\end{array}$ & $\begin{array}{l}\text { Moderately high } \\
\text { testing rates } \\
\text { compared to their } \\
\text { population. With } \\
\text { respect to the } \\
\text { population size, } \\
\text { Mauritius had } \\
\text { conducted the } \\
\text { highest number of } \\
\text { COVID-19 tests }\end{array}$ \\
\hline Nigeria & $21,18,84,956$ & $26,48,684$ & 12,501 & 1.3 & $\begin{array}{c}\text { The gold } \\
\text { standard is } \\
\text { RT-PCR. }\end{array}$ & $\begin{array}{c}\text { Over } 80 \text { open PCR } \\
\text { laboratories, more than } 20 \\
\text { GeneXpert laboratories, } \\
\text { about } 58 \text { fee-based } \\
\text { laboratories and over } 5 \\
\text { corporate laboratories }\end{array}$ & $\begin{array}{l}\text { Low testing rates } \\
\text { relative to the } \\
\text { country's population }\end{array}$ \\
\hline South Africa & $6,01,51,747$ & $1,58,21,074$ & $2,63,019$ & 26 & $\begin{array}{c}\text { The gold } \\
\text { standard is } \\
\text { RT-PCR. }\end{array}$ & \begin{tabular}{|c} 
Over 120 testing \\
laboratories, various \\
mobile testing \\
laboratories, and over 50 \\
private laboratories
\end{tabular} & $\begin{array}{c}\text { Highest COVID-19 } \\
\text { tests conducted in } \\
\text { Africa. }\end{array}$ \\
\hline Tanzania & $6,16,45,954$ & NA & NA & - & $\begin{array}{c}\text { The gold } \\
\text { standard is } \\
\text { RT-PCR. }\end{array}$ & $\begin{array}{c}\text { Private and public } \\
\text { laboratory across the } \\
\text { country. }\end{array}$ & $\begin{array}{l}\text { Even though there is } \\
\text { lack of coordinated } \\
\text { data of the testing } \\
\text { rates, it is clear that } \\
\text { COVID-19 testing is } \\
\text { suboptimal }\end{array}$ \\
\hline Uganda & $4,73,62,996$ & $15,36,425$ & 32,439 & 3.2 & \begin{tabular}{|c|} 
The gold \\
standard is \\
RT-PCR. \\
\end{tabular} & $\begin{array}{c}22 \text { accredited COVID-19 } \\
\text { testing laboratories }\end{array}$ & $\begin{array}{l}\text { Low testing rates } \\
\text { relative to the } \\
\text { country's population }\end{array}$ \\
\hline Zambia & $1,89,62,511$ & $22,01,555$ & $1,16,100$ & 11.6 & \begin{tabular}{|c|} 
The gold \\
standard is \\
RT-PCR.
\end{tabular} & $\begin{array}{c}\text { More than } 10 \text { COVID-19 } \\
\text { testing laboratories across } \\
\text { government hospitals and } \\
\text { private laboratories among } \\
\text { others }\end{array}$ & $\begin{array}{l}\text { Low testing rates } \\
\text { relative to the } \\
\text { country's population }\end{array}$ \\
\hline
\end{tabular}

https://www.worldometers.info/population/countries-in-africa-by-population/

Table 1: Summary of laboratory testing capacity in the 13 African countries. 


\section{Epidemiology International Journal}

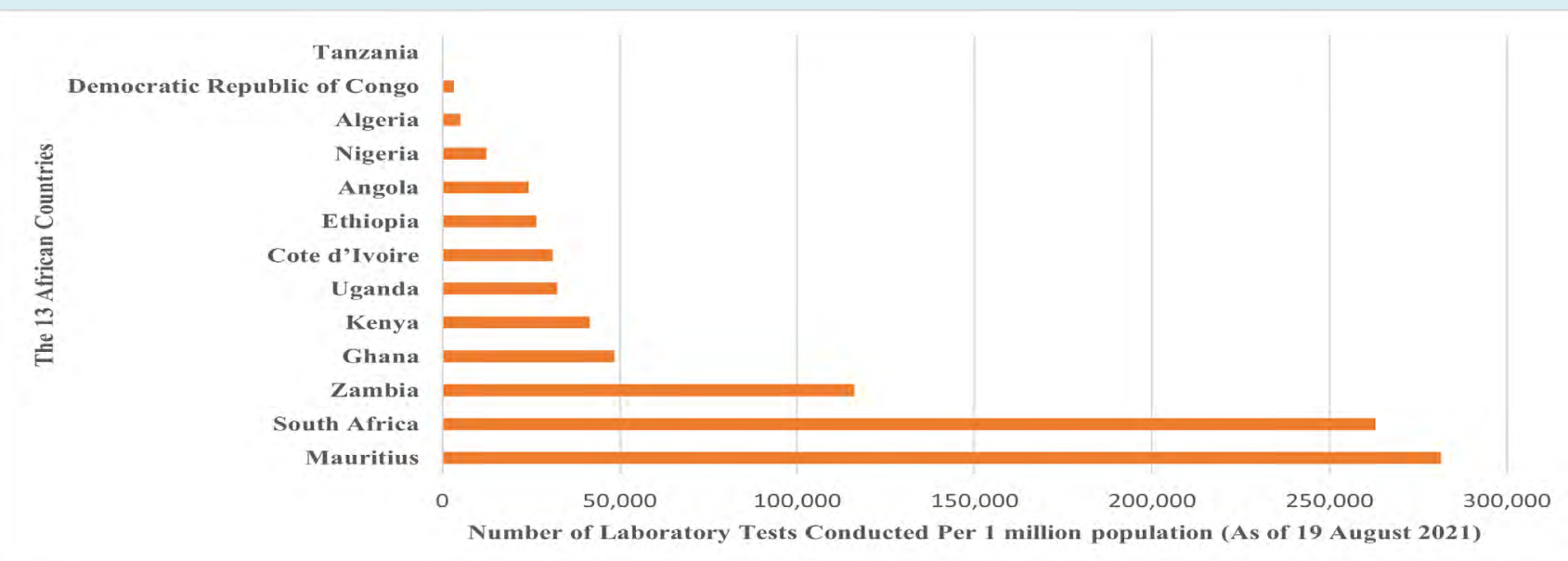

Figure 1: revealed the number of laboratory COVID-19 test conducted per 1 million population in the 13 African countries.

\section{Algeria}

Algeria has reported 190,078 confirmed cases of COVID-19 cases with 4,929 mortalities as of 19th August 2021 and has conducted tests on 230,861 samples14, which constitute $0.5 \%$ of the total population of over 44 million. COVID-19 laboratory testing in Algeria is coordinated and managed by the Institute Pasteur Algeria (IPA), which is based in the capital, Algiers $[12,15,16]$. Even though IPA's gold standard of testing is Reverse Transcription Polymerase Chain Reaction (RT-PCR), rapid test kits and computed tomography tests have been leveraged to increase testing capacity. From only about fifty tests per day by IPA in the early days of the pandemic, the number of daily testing has increased up to 2500 tests through the opening of 29 laboratories in Oran, Constantine, and Ouargla (IPA annexes), and university and hospital laboratories. Despite the increase in testing, the capacity is still very much lower relative to the population size $[15,16]$.

\section{Angola}

Angola has recorded 45,175 confirmed cases of COVID-19 with 1,125 mortalities as of 19th August 2021 and has conducted tests on 826,140 samples [14], which constitute $2.4 \%$ of the total population of over 34 million. As of 26 August 2020, Angola has 3 operational COVID-19 testing labs, which perform 300-400 tests/day; the National Laboratory of Instituto Nacional de Investigação em Saúd located in Luanda scored $100 \%$ on the EQAP-satisfactory performance scoring system; RT-PCR, which is the gold standard $[17,18]$. The country was able to increase its testing capacity to 6000 samples per day with the establishment of the Viana Laboratory Diagnostic Center in addition to other existing testing facilities [19]. Viana Laboratory Diagnostic Center, situated in the Viana Special Economic Zone, is the largest molecular biology and serology laboratory in Angola [19]. In addition to COVID-19 testing at this center, effort is underway to set up more RT-PCR laboratories in the provinces of Huambo, Lunda Norte, and Uíge, collaborate with private laboratories and hospitals and roll out rapid diagnostic testing [19]. However, more still needs to be done to understand the full size of the pandemic in the country.

\section{Cote d'Ivoire}

Cote d'Ivoire has recorded 53,089 confirmed cases of COVID-19 with 373 deaths as of 19th August 2021 and has conducted tests on 845,410 samples [14], which constitute $3.1 \%$ of the total population of over 27 million. The country's COVID-19 case was diagnosed at CDC-supported Pasteur Institute of Cote d'Ivoire in Abidjan [20]. As of April 2020, nine (9) testing centers were available and equipped with equipment and health personnel in Abidjan, the epicentre of the pandemic [21]. At the end of April 2020, the Government announced a contribution of 25 billion CFA to the Public Health Response Plan (total 95.5 billion CFA) with the support to scale up additional testing capacities (up to 45 sites nationwide) [22]. The gold standard of COVID-19 testing in Cote d'Ivoire is RT-PCR and efforts are currently being made to increase testing capacity to more than 1000 per day [21]. The size of the pandemic is still yet to be fully understood because of the low testing rates.

\section{Democratic Republic of Congo}

The Democratic Republic of Congo has recorded 53,757 confirmed cases of COVID-19 with 1053 deaths as of 19th August 2021 and has conducted tests on 302,022 samples [14], which constitute $0.3 \%$ of the total population of over 92 million. Of twenty-six provinces, RT-PCR COVID-19 testing is only available in 6 towns (Kinshasa, Matadi, Lubumbashi, 


\section{Epidemiology International Journal}

Goma, Kolwezi, and Mbandaka), and some private centers, about six months into the pandemic [23]. As of September 2020 , the daily testing stood at 900 per day in the Democratic Republic of Congo [24]. The country's National Institute of Biomedical Research (NIBR) is the main testing laboratory of the country and it is responsible for performing all the COVID-19 RT-PCR testing [23]. However, the transportation of samples from remote places to the NIBR has been delayed because of a lack of logistical resources and poor road networks [23]. All these contributed to low testing rates in the country and makes it difficult to understand the size of the pandemic on the continent.

\section{Ethiopia}

Ethiopia has recorded 292,731 confirmed cases of COVID-19 with 4,518 deaths as of 19th August 2021 and has conducted tests on 3,142,116 samples [14], which constitute $2.7 \%$ of the total population of over 118 million. To identify COVID-19 cases, the only approved laboratory diagnostic approach in Ethiopia is the RT-PCR testing [25]. At the beginning of the pandemic, Ethiopia was sending samples to South Africa to conduct the test [25]. The country has slowly set up a testing center at the national reference laboratory and later created more laboratories [26]. Despite this, the national testing capacity is very low in relation to over a $116,000,000$ population size, and the facilities are majorly situated in cities, research institutes, hospitals, and laboratories across Ethiopian universities [25,26]. However, as of November 2020, COVID-19 testing had significantly improved and reached over 70 laboratories with a daily capacity of more than 13,000 tests [25].

\section{Mauritius}

Mauritius has recorded 6,460 confirmed cases of COVID-19 with 22 deaths as of 19th August 2021 and has conducted tests on 358,675 samples [14], which constitute $36 \%$ of the total population of over 1.2 million. In Mauritius, laboratory diagnostic testing of unconfirmed cases by PCR commenced on 3 February 2020 and has been beneficial in the diagnosis of the COVID-19 cases as the pandemic progresses [27] The early availability of PCR testing facilities in Mauritius has a positive impact on the country's COVID-19 response [27-29]. Even though at the early days of the outbreak, ten PCR tests were conducted daily, however, 1400 and more PCR tests were now conducted per daily [28] As of January 2021, Mauritius had more than four COVID-19 testing PCR laboratories which are found across private laboratories, and hospitals among others [28]. Additionally, the country is also leveraging the use of rapid antigen tests $[27,29]$. However, more still needs to be done to understand the size of the pandemic in the country [27].

\section{Ghana}

Ghana has recorded 112,928 confirmed cases of COVID-19 with 945 deaths as of 19th August 2021 and has conducted tests on $1,554,519$ samples 14 , which constitute $4.9 \%$ of the total population of over 31 million. The COVID-19 testing started in the country's leading medical research institute, the Noguchi Memorial Institute for Medical Research (NMIMR) of the University of Ghana $[12,30]$. Currently, the research institute is one of the leading primary testing facilities for COVID-19 tests conducted in the country [12,31]. Other laboratories such as Kumasi Centre for Collaborative Research, National Public Health Reference Laboratories, and Council for Scientific and Industrial Research among others, were later equipped for COVID-19 testing $[30,31]$. The country continues to make efforts to strengthen its testing capacity by using GeneXpert platforms, rapid antigen tests, and including the 100 Regional and District Tuberculosis Gene Expert Laboratories for COVID-19 testing [12]. Besides, the government also adopted innovative strategies like the use of drones to deliver test samples and result to and from the testing centres respectively [32]. Besides, initially Ghana implemented a single sample rRTPCR testing before switching to a sample pooling strategy which subsequently improved the testing capacity in the country [33]. Despite this, the country's testing capacity is low relative to its population.

\section{Kenya}

Kenya has recorded 225,663 confirmed cases of COVID-19 with 4404 deaths as of 19th August 2021 and has conducted tests on 2,287,443 samples [14], which constitute $4.2 \%$ of the total population of over 55 million. On 12 March 2020 , the country's national health authorities confirmed the first COVID-19 case in its capital city, Nairobi, at the National Influenza Centre Laboratory, one of the country's national public health laboratories.34 The gold standard of COVID-19 testing in Kenya is RT-PCR [34,35]. As of April 2021, the country had more than 45 COVID-19 testing laboratories across government hospitals and private laboratories among others [36]. The country also embarks on mass testing with the use of rapid antigen tests and also has a guideline for its use [35]. Despite this, the size of the pandemic is still yet to be fully understood [34].

\section{Nigeria}

Nigeria has recorded 183,444 confirmed cases of COVID-19 with 2,229 deaths as of 19th August 2021 and has conducted tests on $2,648,684$ samples, which constitute $1.3 \%$ of the total population of over 211 million. The Nigeria Centre for Disease Control (NCDC) is the highest government 


\section{Epidemiology International Journal}

agency that is responsible for infectious disease outbreaks response and preparedness in Nigeria [37]. The agency is also in charge of coordinating COVID-19 laboratory response in the country [37-39]. As of August 2021, Nigeria has over 80 open PCR laboratories, more than 20 GeneXpert laboratories, about 58 fee-based laboratories, and over 5 corporate laboratories [40] Nigeria was also the pioneer African country to publish the first genome sequence of SARS-CoV-2 on the continent $[4,41]$ The country is also exploring serological testing and rapid antigen testing to increase its testing capacity.12 Despite this, the country's testing capacity is low relative to its population $[38,39]$.

\section{South Africa}

South Africa has recorded 2,652,652 confirmed cases of COVID-19 with 78,694 mortalities as of 19th August 2021 and has conducted tests on 15,821,074 samples, which constitute about $26 \%$ of the total population of over 60 million. National Health Laboratory Service (NHLS) coordinates COVID-19 testing in South Africa, being the biggest diagnostic pathology service provider in the country [42]. NHLS has over 120 testing laboratories across the country and as of August 2021, the country has procured mobile sampling and testing laboratory units which were deployed nationwide to expand COVID-19 testing services [43]. The major testing strategies used across various testing units are PCR and rapid antigen methods. Serology testing has also be leveraged to understand infectivity rate in South Africa [44] and over 50 private laboratories are also involved in COVID-19 testing [45] Even though the country has conducted the highest COVID-19 tests in Africa, more still needs to be done to understand the full size of the outbreak.

\section{Uganda}

Uganda has recorded 97,453 confirmed cases of COVID-19 with 2,931 deaths as of 19th August 2021 and has conducted tests on 1,536,425 samples, which constitute about $3.2 \%$ of the total population of over 47 million. In early February 2020, RT-PCR testing started at the Uganda Virus Research Institute [46]. As of June 2021, Uganda has 22 accredited COVID-19 testing laboratories with the PCR being the gold standard of diagnosis [47]. The country also utilizes rapid antigen and serological testing to understand the size of the pandemic [48]. However, more still needs to be done.

\section{Zambia}

Zambia has recorded 203,553 confirmed cases of COVID-19 with 3,564 deaths as of 19th August 2021 and has conducted tests on 2,201,555 samples, which constitute about $11.6 \%$ of the total population of over 18 million. In the early days of the pandemic, the University of Zambia School of Veterinary Medicine BSL-3 Laboratory in Lusaka, Zambia, and the University Teaching Hospital (UTH) Virology Biosafety Level-2 (BSL-2) Laboratory were identified as national COVID-19 diagnostic testing centres [49]. All COVID-19 diagnoses were confirmed using PCR testing. As of August 2021, the country had more than 10 COVID-19 testing laboratories across government hospitals and private laboratories among others [50]. Rapid antigen tests have also been leveraged to increase the testing rates [51]. Despite the increase in testing, the capacity is still very much lower relative to the population size [52].

\section{Tanzania}

Tanzania has recorded 16,970 confirmed cases of COVID-19 with 50 mortalities as of 15th August 2021 [53]. This statistics clearly does not reveal the size of the pandemic in the country due to pervasive COVID-19 denialism propagated by the Late John Magufuli [2,54]. Additionally, during the late John Magufuli era as Tanzania's president, the country failed to share COVID-19 statistics with WHO and other international health authorities. The denialism has led to a lack of government investment in COVID-19 response, including laboratory capacity building. Even though the current regime of President Samia Suluhu Hassan continues to make efforts to strengthen the country's COVID-19 response [55], more still needs to be done to strengthen the Tanzanian testing capacity. Currently, there are various COVID-19 testing laboratories across Tanzania both public and private. The major testing strategies used across various testing centers are PCR and rapid antigen methods [56]. However, there is a lack of coordinated data on the total number of COVID-19 tests conducted in the country.

\section{Low COVID-19 Cases, Testing Rates and Capacity in the 13 African Countries}

Currently, no African country has assessed the "true" total number of people infected with COVID-19 which implies that confirmed cases may not truly represent the size of the pandemic on the continent. This is because confirmed cases counts depend on how many people have been tested for COVID-19 [57]. More than just recording the confirmed cases, African countries need to adopt mass testing [58]. As seen in Table 1, the testing rate for COVID-19 in the majority of the African countries is low relative to the population size. This would definitely make it difficult to understand the full extent of the pandemic on the continent. Additionally, our study revealed that higher testing rates increase the possibility of documenting new COVID-19 cases. For example, South Africa has the highest COVID-19 cases and tests conducted on the continent. This emphasizes the need for African countries to 


\section{Epidemiology International Journal}

strengthen their testing capacity for COVID-19.

COVID-19 testing requirements vary across African countries; however, most African countries have adopted selective testing for hospitalized patients with respiratory conditions and other COVID-19 symptoms, residents in the area of high COVID-19 density, contacts of known positive cases, health care workers, and returnee citizens [59]. This selective testing may make it difficult to understand the size of the pandemic on the continent. This is concerning because asymptomatic COVID-19 patients can also transmit the virus [60-62]. However, the selective approach to testing is due to the fact that African countries do not have the needed extensive laboratory capacity to test for all cases. Additionally, most African countries are making efforts to be prudent with the use of the limited testing kits and other resources that are available. Even though the low COVID-19 cases on the African continent may be due to low testing rates, capacity, as well as poor diseases surveillance [63-65], researchers have made efforts to justify this $[11,63]$. First is a swift response to curb the outbreak in the early days of the pandemic $[66,67]$.

Evidence has shown that many African countries have ramped up response and preparedness strategies well before cases were reported on the continent $[4,68,69]$. Precautionary health measures - including avoiding handshakes, regular hand washing, physical distancing, and wearing of face masks - were quickly introduced.4 Second, previous experience in responding to outbreaks may have provided groundwork to prepare for the COVID-19 outbreak $[4,69,70]$ African countries such as the Democratic Republic of Congo, which battled a major outbreak of Ebola - had also mastered the public health measures that have been used to prevent COVID-19, including isolating the infected, screening of travellers, and contact tracing [71,72]. Third, compared to other regions, African has a young population [73-75] and globally, most of those who have a severe infection have been part of the older population [76], while Africa is home to the world's youngest population with a median age of 19 years, according to United Nations data [77]. Fourth, even though there is still limited evidence11, there are proposition that Africa's weather condition could be responsible for low COVID-19 cases [78,79]. However, this hypothesis alone cannot fully explain the current low number of cases in affected African countries. Lastly, the low population density in Africa may be responsible for low COVID-19 cases on the continent [80]. The virus spreads quicker and more easily in crowded, enclosed, and noisy spaces [81], and many communities on the continent are rural and widely dispersed [82], which may slow down the virus transmissibility. Additionally, in many African countries, the outbreak hotspots are in cities with high population density.

\section{Challenges Facing COVID-19 Laboratory Testing in Africa}

COVID-19 laboratory testing is not without its challenges in Africa. COVID-19 testing insufficiency in Africa is attributed to both inadequate laboratory resources and a dearth of human resources. This is worrisome because the hallmark of an effective response to outbreak control is early diagnosis, which is even more important for the COVID-19 outbreak because of the possibility of transmission of the virus by asymptomatic patients. Prior to the COVID-19 pandemic, response efforts to outbreaks in Africa were limited by insufficient laboratory equipment such as PCR [83]. Many African countries e.g. Uganda [84], Nigeria [85], Ethiopia [86], and others, have reported a shortage of COVID-19 testing kits and molecular diagnostic equipment. The travel ban imposed in the early days of the pandemic has also made importation of testing resources difficult (logistics constraint). This has made many African governments restrict COVID-19 testing to individuals that met specified criteria (targeted testing) as opposed to mass testing.

Reports have also shown that some African countries continue to make effort to make local testing kits $[87,88]$. Many African countries have acquired more PCR machines and other testing resources with the support of the World Health Organization (WHO), Africa Center for Diseases Control, international grants, and other philanthropic individuals and organizations.84 The reliance on aids would not be sustainable in the long run [89], and this has contributed to the high cost of COVID-19 test reported in some African countries [90] This elevates the need for African countries to strengthen local production of test kits and make COVID-19 tests affordable. According to WHO, a non-propagative COVID-19 diagnosis should be done in a bio-safety class II level-P2 laboratory [91] Yet, the number of laboratories with such facilities are very limited across Africa and most diagnostic centers are not well-equipped to handle the enormous in-flow of samples to be tested and the lack of reference laboratories in some African countries is another concern.25 Furthermore, shortage of certified biomedical engineers, weak statistical capacity, poor management of laboratory data, human errors and delayed testing and the presence of limited skilled clinical laboratories professionals are also some of the challenges facing COVID-19 testing on the continent $[25,92]$. However, African countries and other stakeholders continue to invest in training more people on how to use PCR, GeneXpert and other testing methods for COVID-19 [93].

Weak surveillance systems is also another challenge facing COVID-19 laboratory testing on the continent.65 Effective surveillance is crucial for case finding, contact 


\section{Epidemiology International Journal}

tracing and actual testing of suspected or probable cases [94]. A comprehensive review of surveillance systems in 13 African countries (Mauritius, Algeria, Nigeria, Angola, Cote d'Ivoire, the Democratic Republic of the Congo, Ghana, Ethiopia, South Africa, Kenya, Zambia, Tanzania, and Uganda) revealed that COVID-19 surveillance faced various challenges such as shortage of skilled human resources resulting in poor data management, stigma, and misinformation, complexities of ethical considerations, diagnostic insufficiency, the burden of co-epidemic surveillance, and weak health systems, among others. More so, the World Bank reported that about 6 out of every 10 individuals in Sub-Saharan Africa are inhabitant of rural communities [95]. Due to geographical and transportation barriers, moving samples from rural communities to the laboratory testing centers has been challenging. Strengthening COVID-19 surveillance systems, together with effective laboratory systems, would facilitate a full understanding of the size of the pandemic on the continent. All the aforementioned challenges can be attributed to the overall African weak health systems in each country, which are strained and have low capacity to respond to a pandemic. The COVID-19 outbreak has made Africa to realize how laboratories are an essential part of the health systems and every patient deserves timely, accessible, affordable, and correct diagnosis and it takes careful organization, planning, and implementation of laboratory quality management systems.

\section{Study Limitations}

This study does not include some databases such as Scopus and Web of Science. However, the databases used in the study provided key insights on the topic and will add value to strengthen COVID-19 laboratory testing capacity in Africa. Second, only papers written in English language are included. Even though most of the COVID-19 papers are published in English, there is a possibility that we may have excluded some studies in local languages. Third, the unsystematic search method used in the study may lead to the subjective selection of articles and consequently add bias to the overall interpretation of findings. The researchers considered this limitation in their search strategy, but with limited published evidence in the literature, they prioritized the need for an overview of this selected topic.

\section{Conclusion}

The COVID-19 outbreak has uncovered deficiencies in the diagnostic systems in many countries globally and African countries are not an exception. This study revealed that there is a low laboratory testing capacity in selected African countries and that the laboratory response to COVID-19 presents with significant challenges. This emphasizes the need to strengthen and invest in laboratory testing capacity for the present outbreak and future public health emergencies across Africa.

\section{References}

1. Elebesunu EE, Oke GI, Adebisi YA, Nsofor IM (2021) COVID-19 calls for health systems strengthening in Africa: A case of Nigeria. Int J Health Plann Manage 36(6): 2035-2043.

2. Adebisi YA, Rabe A, Lucero Prisno DE (2021) Risk communication and community engagement strategies for COVID-19 in 13 African countries. Health Promot Perspect 11(2): 137-147.

3. Gaye B, Khoury S, Cene CW, Kingue S, Guetta RN, et al. (2020) Socio demographic and epidemiological consideration of Africa's COVID-19 response: what is the possible pandemic course?. Nat Med 26(7): 996-999.

4. Lucero Prisno DE, Adebisi YA, Lin X (2020) Current efforts and challenges facing responses to $2019-n \mathrm{CoV}$ in Africa. Glob Health Res Policy 5: 21.

5. WHO (2021) Coronavirus Update.

6. WHO (2021) Technical documents.

7. WHO (2021) Report of the WHO-China Joint Mission on Coronavirus Disease 2019 (COVID-19).

8. WHO (2021) 2019 Novel Coronavirus (2019-nCoV): Strategic preparedness and response plan.

9. WHO (2020) The African region reinforces preparedness for novel coronavirus.

10. WHO (2021) COVID-19.

11. Chitungo I, Dzobo M, Hlongwa M, Dzinamarira T (2020) COVID-19: Unpacking the low number of cases in Africa. Public Health Pract (Oxf) 1: 100038.

12. Odeyemi FA, Adekunle IA, Ogunbanjo OW, Folorunso JB, Akinbolaji T, et al. (2020) Gauging the laboratory responses to coronavirus disease (COVID-19) in Africa. J Public Aff 27: e2280.

13. WHO (2020) Covid-19 in Africa: Response areas.

14. Worldometer (2021) COVID-19.

15. Downtoearth (2021) COVID-19: North Africa most affected in entire continent with $68 \%$ of all deaths.

16. Lounis M (2021) Epdemiology of coronavirus disease 2020 (COVID-19) in Algeria. New Microbes New Infect 39: 100822 . 
17. WHO (2020) COVID-19 African Situation Report.

18. Sebastiao CS, Neto Z, Martinez P, Jandondo D, Antonio J, et al. (2021) Sociodemographic characteristics and risk factors related to SARS-CoV-2 infection in Luanda, Angola. PLoS One 16(3): e0249249.

19. All Africa (2021) Angola Strengthens Covid-19 Testing Capacity.

20. CDC (2021) Cote d Ivoire HIV Laboratory Partners with CDC to Chart New Paths in COVID-19 Testing.

21. (2021) Coronavirus In Cote D'ivoire: 45 Testing Centers Planned To Strengthen The Health Response.

22. Unicef (2021) Cote d Ivoire Coronavirus (COVID-19) Situation Report No. 3 Internal.

23. Juma CA, Mushabaa NK, Salam FA, Ahmadi A, LuceroPrisno DE (2020) COVID-19: The Current Situation in the Democratic Republic of Congo. Am J Trop Med Hyg 103(6): 2168-2170.

24. Relief Web (2020) COVID-19 Democratic Republic of Congo.

25. Mulu A, Bekele A, Abdissa A, Balcha TT, Habtamu M, et al. (2021) The challenges of COVID-19 testing in Africa: the Ethiopian experience. Pan Afr Med J 38: 6.

26. Kebede A, Lanyero B, Beyene B, Mandalia ML, Melese D, et al. (2021) Expanding molecular diagnostic capacity for COVID-19 in Ethiopia: operational implications, challenges and lessons learnt. Pan Afr Med J 38: 68.

27. Sun MC, Lan Cheong Wah CB (2020)Lessons to be learnt from the COVID-19 public health response in Mauritius. Public Health Pract (Oxf) 1: 100023.

28. Relief Web (2021) Empowering Laboratory Professionals on Quality Management Systems during the Training of Trainers.

29. WHO (2021) Management And Prevention Of Covid-19.

30. Acheampong G, Owusu M, Nkrumah B, Boadi PO, Opare DA, et al. (2021) Laboratory capacity in COVID-19 diagnosis and the need to enhance molecular testing in Ghana. Global Security: Health Science and Policy 6(1): 10-17.

31. Mitchell N (2021) 77\% growth in English-taught programmes outside the 'big four'. University World News.

32. Afriyie DK, Asare GA, Amponsah SK, Godman B (2020) COVID-19 pandemic in resource-poor countries: challenges, experiences and opportunities in Ghana. J Infect Dev Ctries 14(8): 838-843.

33. Nyazika TK, Kaela R, Mugoni M, Musomekwa K, Baafour EK, et al. (2020) Implementation of Antibody Rapid Diagnostic Testing versus Real-Time Reverse Transcription-PCR Sample Pooling in the Screening of COVID-19: a Case of Different Testing Strategies in Africa. mSphere 5(4): e00524- e00530.

34. Aluga MA (2020) Coronavirus Disease 2019 (COVID-19) in Kenya: Preparedness, response and transmissibility. J Microbiol Immunol Infect 53(5): 671-673.

35. (2021) COVID-19 Antigen Rapid Diagnostic Testing Interim Guide Kenya, Ministry of Health, pp: 1-2.

36. COVID-19 (2021) Testing Laboratories. Ministry of Health, pp: 1-2.

37. National Strategy to Scale up Access to Coronavirus Disease Testing in Nigeria (NCDC) (2021) COVD-19 Testing Strategy, pp: 1-32.

38. Nwafor CD, Ochu CL, Elimian K, Oladejo J, Ilori E, et al. (2020) Nigeria's public health response to the COVID-19 pandemic: January to May 2020. J Glob Health 10(2): 020399.

39. Abayomi A, Balogun MR, Bankole M, Thomas AB, Mutiu B, et al. (2021) From Ebola to COVID-19: emergency preparedness and response plans and actions in Lagos, Nigeria. Global Health 17(1): 79.

40. NCDC (2021) Private Labs.

41. Shey M, Okeibunor JC, Yahaya AA, Herring BL, Tomori O, et al. (2020) Genome sequencing and the diagnosis of novel coronavirus (SARS-COV-2) in Africa: how far are we?. Pan Afr Med J 36: 80.

42. NHLS' preparedness for testing to meet COVID-19 demands. National Health Laboratory Service.

43. (2021) National Health Laboratory Service.

44. (2021) Guidance on the use of SARS CoV-2 Antibody Tests. Health Republic of South Africa.

45. Private Laboratory (2021) Health Republic of South Africa.

46. Nalumansi A, Lutalo T, Kayiwa J, Watera C, Balinandi S, et al. (2020) Field evaluation of the performance of a SARSCoV-2 antigen rapid diagnostic test in Uganda using nasopharyngeal samples. Int J Infect Dis 104: 282-286.

47. Accredited COVID-19 Laboratory in Uganda (2021) 


\section{Epidemiology International Journal}

Ministry of Health.

48. (2021) Uganda launches COVID-19 rapid test kit, eyes Africa market. Reuters.

49. Simulundu E, Mupeta F, Kapata PC, Saasa N, Changula K, et al. (2021) First COVID-19 case in Zambia-Comparative phylogenomic analyses of SARS-CoV-2 detected in African countries. Int J Infect Dis 102: 455-459.

50. List of laboratories (2021) Health Screening Document.

51. (2021) Global Fund supplies Zambia 81,250 COVID-19 test kits. Xinhuanet.

52. Mulenga LB, Hines JZ, Fwoloshi S, Chirwa L, Siwingwa $M$, et al. (2021) Prevalence of SARS-CoV-2 in six districts in Zambia in July, 2020: a cross-sectional cluster sample survey. Lancet Glob Health 9(6): e773-e781.

53. (2021) Outbreak Brief 83: Coronavirus Disease 2019 (COVID-19) Pandemic. Africa CDC.

54. Buguzi S (2021) Covid-19: Counting the cost of denial in Tanzania. BMJ 373: n1052.

55. Mhagama H (2021) Tanzania: Samia Changes Covid-19 Handling Approach. All Africa.

56. COVID-19 Information (2021) US Embassy in Tanzania.

57. (2021) Recommendations for national SARS-CoV-2 testing strategies and diagnostic capacities. World Health Organization pp: 1-16.

58. Adebisi YA, Oke GI, Ademola PS, Chinemelum IG, Ogunkola IO, et al. (2020) SARS-CoV-2 diagnostic testing in Africa: needs and challenges. Pan Afr Med J 35(S2): 4.

59. Kobia F, Gitaka J (2020) COVID-19: Are Africa's diagnostic challenges blunting response effectiveness?. AAS Open Res 3: 4 .

60. Nogrady B (2020) What the data say about asymptomatic COVID infections. Nature 587(7835): 534-535.

61. Huff HV, Singh A (2020) Asymptomatic Transmission during the Coronavirus Disease 2019 Pandemic and Implications for Public Health Strategies. Clin Infect Dis 71(10): 2752-2756.

62. Johansson MA, Quandelacy TM, Kada S, Prasad PV, Steele M, et al. (2021) SARS-CoV-2 Transmission From People Without COVID-19 Symptoms. JAMA Netw Open 4(1): e2035057.

63. Njenga MK, Dawa J, Nanyingi M, Gachohi J, Ngere I, et al. (2020) Why is There Low Morbidity and Mortality of
COVID-19 in Africa?. Am J Trop Med Hyg 103(2): 564569.

64. Adebisi YA, Rabe A, Lucero Prisno DE (2021) COVID-19 Surveillance Systems in 13 African countries. Health Promot Perspect.

65. Aborode AT, Hasan MM, Jain S, Okereke M, Adedeji OJ, et al. (2021) Impact of poor disease surveillance system on COVID-19 response in africa: Time to rethink and rebuilt. Clin Epidemiol Glob Health 12: 100841.

66. Loembé MM, Tshangela A, Salyer SJ, Varma JK, Ouma AEO, et al. (2020) COVID-19 in Africa: the spread and response. Nat Med 26(7): 999-1003.

67. Kuguyo O, Kengne AP, Dandara C (2020) Singapore COVID-19 Pandemic Response as a Successful Model Framework for Low-Resource Health Care Settings in Africa?. OMICS 24(8): 470-478.

68. Nachega JB, Atteh R, Ihekweazu C, Sam Agudu NA, Adejumo P, et al. (2021) Contact Tracing and the COVID-19 Response in Africa: Best Practices, Key Challenges, and Lessons Learned from Nigeria, Rwanda, South Africa, and Uganda. Am J Trop Med Hyg 104(4): 1179-1187.

69. Maeda JM, Nkengasong JN (2021) The puzzle of the COVID-19 pandemic in Africa. Science 371(6524): 27-28.

70. (2020) In the Face of Coronavirus, African Countries Apply Lessons from Ebola Response. World Bank.

71. (2020) 10th Ebola outbreak in the Democratic Republic of the Congo declared over; vigilance against flare-ups and support for survivors must continue. World Health Organization.

72. Soy A (2020) Coronavirus in Africa: Five reasons why Covid-19 has been less deadly than elsewhere. BBC.

73. Diop BZ, Ngom M, Biyong CP, Pougué Biyong JN (2020) The relatively young and rural population may limit the spread and severity of COVID-19 in Africa: a modelling study. BMJ Glob Health 5(5): e002699.

74. Saalim K, Sakyi KS, Zohra FT, Morrison E, Owusu P, et al. (2021) Reported health and social consequences of the COVID-19 pandemic on vulnerable populations and implemented solutions in six West African countries: A media content analysis. PLoS One 16(6): e0252890.

75. Adams J, MacKenzie MJ, Amegah AK, Ezeh A, Gadanya MA, et al. (2021) The Conundrum of Low COVID-19 Mortality Burden in sub-Saharan Africa: Myth or Reality?. Global Health Sci Pract 9(3): 433-443. 
76. Perrotta F, Corbi G, Mazzeo G, Boccia M, Aronne L, et al. (2020) COVID-19 and the elderly: insights into pathogenesis and clinical decision-making. Aging Clin Exp Res 32(8): 1599-1608.

77. (2015) Youth population trends and sustainable development. United Nations, pp: 1-4.

78. Meo SA, Abukhalaf AA, Alomar AA, Aljudi TW, Bajri HM, et al. (2020) Impact of weather conditions on incidence and mortality of COVID-19 pandemic in Africa. Eur Rev Med Pharmacol Sci 24(18): 9753-9759.

79. Bukhari Q, Massaro JM, D’Agostino RB, Khan S (2020) Effects of Weather on Coronavirus Pandemic. Int J Environ Res Public Health 17(15): 5399.

80. Bamgboye EL, Omiye JA, Afolaranmi OJ, Davids MR, Tannor EK, et al. (2021) COVID-19 Pandemic: Is Africa Different?. J Natl Med Assoc 113(3): 324-335.

81. Noorimotlagh Z, Jaafarzadeh N, Martínez SS, Mirzaee SA (2021) A systematic review of possible airborne transmission of the COVID-19 virus (SARS-CoV-2) in the indoor air environment. Environ Res 193: 110612.

82. Ogunkola IO, Adebisi YA, Imo UF, Odey GO, Esu E, et al. (2020) Rural communities in Africa should not be forgotten in responses to COVID-19. Int J Health Plann Manage 35(6): 1302-1305.

83. Adepoju P (2020) Africa's struggle with inadequate COVID-19 testing. Lancet Microbe 1(1): e12.

84. (2021) Uganda: Why Poor Ugandans Are Losing Covid Fight. All Africa.

85. Amzat J, Aminu K, Kolo VI, Akinyele AA, Ogundairo JA, et al. (2020) Coronavirus outbreak in Nigeria: Burden and socio-medical response during the first 100 days. Int J
Infect Dis 98: 218-224.

86. Geto Z, Gebremichael S, Belete MA, Gedefie A, Molla G, et al. (2021) The Escalating Magnitude of COVID-19 Infections among the Northeastern Ethiopia Region: A Community-Based Cross-Sectional Study. Int J Microbiol.

87. Busari S, Sunday O (2020) Nigerian scientists develop cheaper and faster Covid-19 test kits. CNN.

88. (2021) Africa's Scientific Solutions and Innovation in the Fight against COVID-19. The World Bank.

89. Songok E (2020) A locally sustainable approach to COVID-19 testing in Africa. Lancet Microbe 1(5): e197.

90. (2020) How Nigeria Ranks In COVID-19 Test Price Compared To Other African Countries. Sahara Reporters.

91. Hong KH, Lee SW, Kim TS, Huh HJ, Lee J, et al. (2020) Guidelines for Laboratory Diagnosis of Coronavirus Disease 2019 (COVID-19) in Korea. Ann Lab Med 40(5): 351-360.

92. Hadaya J, Schumm M, Livingston EH (2020) Testing Individuals for Coronavirus Disease 2019 (COVID-19). JAMA 323(19): 1981.

93. Ondoa P, Kebede Y, Loembe MM, Bhiman JN, Tessema SK, et al. (2020) COVID-19 testing in Africa: lessons learnt. Lancet Microbe 1(3): e103-e104.

94. Kucharski AJ, Klepac P, Conlan AJK, Kissler SM, Tang ML, et al. (2020) Effectiveness of isolation, testing, contact tracing, and physical distancing on reducing transmission of SARS-CoV-2 in different settings: a mathematical modelling study. Lancet Infect Dis 20(10): 1151-1160.

95. Rural population-Sub-Saharan Africa. World Bank. 